\title{
Urban Environment and Social Health of the Elderly: A Critical Discussion on Physical, Social and Policy Environments
}

\author{
By Sara Alidoust* \\ Gordon Holden ${ }^{*}$ \\ Caryl Bosman
}

\begin{abstract}
A key question facing planners is how to design new and develop existing urban environments to improve the social health of older adults, and consequently improve their overall health and wellbeing. Unfortunately research relating to the influence of the environment on the social health of the elderly lacks a clear definition of 'environment'. As a result the differing impacts of environment, however defined, on social health are not fully understood. This is an increasingly important area of research given the world's ageing population. This paper offers a critical review of the environment literature, with a specific focus on the how the physical, social, and policy dimensions of the environment influence the social life of the elderly; social life being an important component of social health. The paper investigates multiple environmental factors at different levels of influence on social life. It also provides a clear classification of environmental features that enable or inhibit social life. Drawing on the literature reviewed, there are manifold associations between physical, social, and policy environmental determinants of social health which need to be understood and prioritised. Developing age-friendly cities, where elderly people are socially active, results from a complex interplay of all of the determinants. This paper identifies the major gaps in current literature in this field and concludes with discussing key policy implications for planners. It offers areas for further research to improve the social health of the elderly through design of the urban environment.
\end{abstract}

\section{Introduction}

Worldwide, the proportion of people aged 60 and over is growing (WHO, 2002). At the same time, urban population growth is expected to continue. It is estimated that by 2030 around 3 out of every 5 people will live in urban areas

${ }^{*}$ PhD Student, Griffith UniversityAustralia.

${ }^{\dagger}$ Discipline Head, Griffith University, Australia.

${ }^{\star}$ Senior Lecturer, Griffith University, Australia. 
(WHO, 2007). Similar to the broader population, the world's elderly population is continuing to become more urbanised. This trend contradicts the image of urban areas as a place that attracts younger and economically active age groups. Urban growth and the increasing tendency towards ageing in place have been responsible for the world's current demographic structure (Phillips, Siu, Yeh, \& Cheng, 2005).

Ageing is a complex process in which both personal and environmental factors are influential (Clarke \& Nieuwenhuijsen, 2009). Because of the urbanisation of the world's population, consideration of the urban environment and its dimensions is essential in the process of ageing. In this paper, the goal is to understand the interrelationships between the urban environment and the social health- one of the main components of the overall health (WHO, 1946) of the elderly. Particular focus of this paper is on the elderly's social life, which is a component of social health. The present paper has two major purposes: (1) to integrate knowledge on the research topic; (2) to identify some of the gaps in the environmental-public health-gerontological research area. Findings of this research will contribute to policy making and city planning aimed at improving the health and well-being of senior citizens. Reference to the elderly in this research is people aged 65 years and over. The terms elderly people, old people, older adults, and seniors used in different sections of this paper, all refer to the people aged 65 years and over unless otherwise specified.

The paper begins by outlining the research method we have used for this research. It then introduces the key concept underpinning this research, social health. The paper then reviews the literature on how the urban environment potentially influences the social life of the elderly. The aim of the review is to classify the environmental determinants of the social life of the elderly into three categories: physical, social, and policy environments. Following this, we discuss the major gaps in the literature and offer key policy implications.

\section{Research Method}

For this paper, we undertook a meta-analysis literature review, looking at published English-language studies that focus on the mechanisms through which different dimensions of the environment influence the elderly's social life. The key words include: physical environment, social environment, policy environment, social life, the elderly. These key words and combination of them were searched in different urban planning, public health, and gerontology databases. We did not rely on one database, since there is very limited overlap between databases from different disciplines (Weaver et al. 2002). Title, abstract and reference list of studies resulted from the search were scanned to find relevant studies. We selected the studies that focus on the social life of the elderly outside their immediate family and workplace. Studies on the rural environment have been excluded from our research. In addition, the focus of our research was on the studies that found an association between the social life of the elderly and features of physical, social, and policy environments. 
Thus, the studies on how to address these features were not included in our research.

Applying these parameters, a total of 38 studies have been critically reviewed. The time frame of the studies reviewed is 1946 to 2013. In this literature review, it is attempted to refer to the most current literature in this field, however, a number of the studies date back to 1970s and 1990s, which highlights the need to update the knowledge about this topic. Selected studies include both academic and practice based literature from all over the world. The synthesis of these studies informed the key themes of this paper, and also revealed some of the gaps in current literature in this field.

\section{An Ecological Approach to the Social Health of the Elderly}

A focus on broader determinants of health that includes environmental interventions is consistent with an ecological approach to health (Institute of Medicine of the National Academies, 2003). This approach targets every available means that has a potential to contribute to health. It often involves long-standing changes to different types of environment, including the physical, social, and policy environments (Crosby, Salazar, \& DiClemente, 2013). The Ottawa Charter for Health Promotion (WHO, 1986) has determinedly adopted an ecological perspective (Dumont, 2009) by referring to the ability of individuals in "changing or coping with the environment" as a way to achieve health (WHO, 1986). Thus, as Dumont (2009) argued, achieving health is consistent with the possibility to live harmoniously in an environment that provides its residents with adequate resources.

World Health Organisation (WHO) (1946) defined health as 'a state of complete physical, mental, and social well-being'. Among these three components of health, social health has not received enough attention in environmental-public health-gerontological research studies. Social health refers to individuals' interpersonal ties and the degree to which they involve in the community (Donald, Ware Jr, Brook, \& Davies-Avery, 1978). A review of literature clarified four main areas of the social health of individuals: (1) family; (2) work; (3) community involvement; (4) social life (e.g., friendships) (Gurland et al. 1972; Greenblatt, 1976; Renne, 1974). In this paper, the influences of the urban environment on the social life, the fourth area of social health, of the elderly is critically discussed. Findings of this study are illustrated in a framework (Figure 1) which is developed from the literature review. In this framework, features of the urban environment that influence the social life of the elderly are classified into three categories: physical, social, and policy environments. These features are discussed in the next sections of the paper. 
Figure 1. A Framework Drawn from the Current Literature to Present how Urban Environments Influence the Social Life of the Elderly

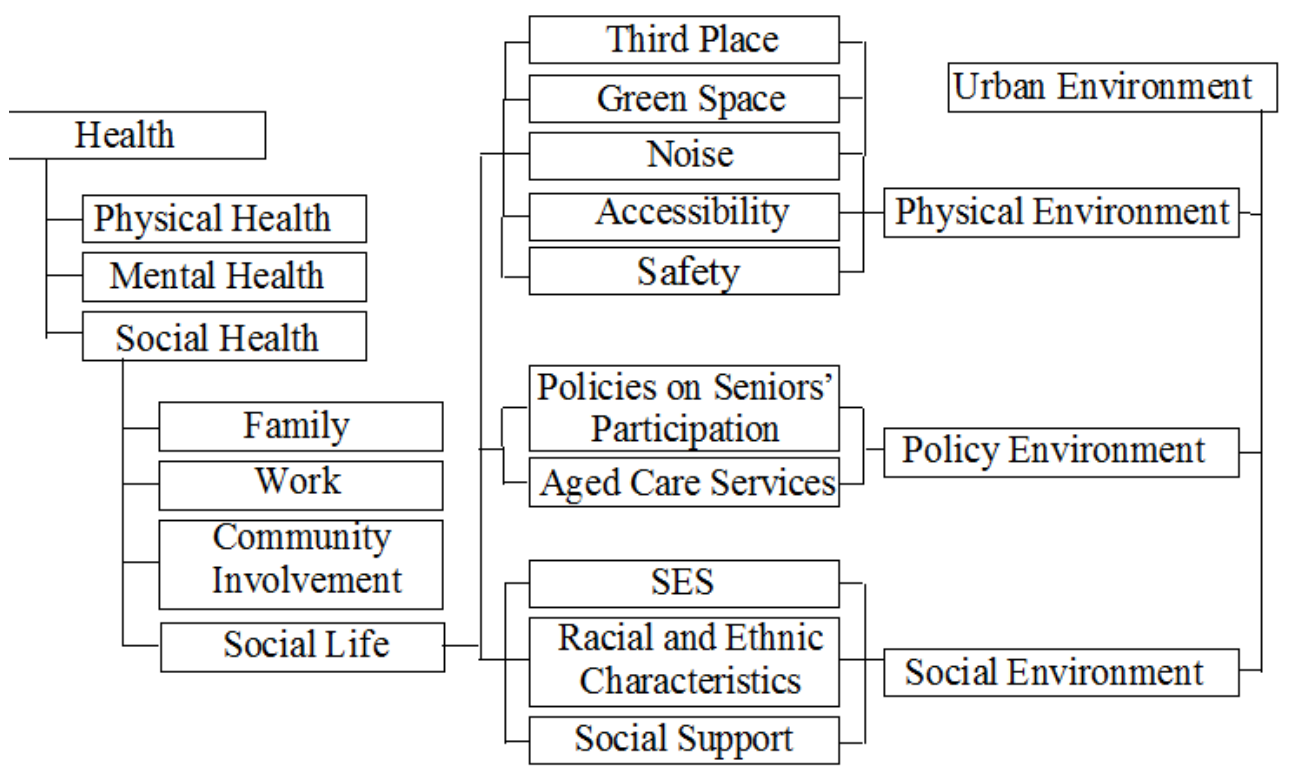

Source: Authors, 2014

\section{Physical Environment}

Drawing on the literature reviewed, the main features of the physical environment found to be influential in the social life of the elderly can be divided into two categories. The first group are those that have an overt or active influence, by providing social interaction opportunities. These features include green spaces and third places. The second group consists of features of the physical environment that have a covert or passive influence through the design of the urban environment. These features include noise, accessibility, and safety.

\section{Active Features of the Physical Environment}

There is a considerable body of research that demonstrates the role of the third place in overtly influencing the social life of the elderly. A third place is defined as a place that is not the first place (home) and is not the second place (work/school); it is where anyone can go and interact with others (Oldenburg, 1989). Rosenbaum (2006) conducted a study to develop a framework that illustrates how and why third places are important to the elderly. His study revealed that third places provide opportunities for older consumers to fulfil their companionship and emotional support as well as consumption needs/requirements. A similar study by Cheang (2002) also revealed the importance of a fast-food restaurant as a place that facilitates the naturally occurring relationships between the elderly. 
Green spaces are also features of the physical environment that overtly influence opportunities for social interaction. This is demonstrated in a study by Kweon, Sullivan, and Wiley (1998), who investigated the role of the physical environment in promoting the social life of the elderly. Their study revealed that the use of green outdoor common spaces increases and strengthens social ties among elderly neighbours.

\section{Passive Features of the Physical Environment}

The level of noise in the environment impacts on the elderly's ability to interact with others. Since the ability to hear lessens with age, elderly people have more difficulty carrying out conversations in noisy environments (Kweon et al., 1998). Hearing loss impairs the exchange of information for the elderly, and consequently impacts on their quality of life, particularly their communication and interaction with others (Ciorba et al., 2012).

Accessibility of the urban environment and its impacts on the elderly's social life has been broadly discussed in the literature. Since loss of mobility increases with age (Guralnik et al., 1993), the social life of the elderly is associated with the accessibility of their environment. Transport is a main indicator of accessibility which can play an important role in the social life of the elderly (Banister \& Bowling, 2004; Phillips et al., 2005). A study by WHO (2007) revealed an association between accessibility of transport services and the level of the social life of the elderly. A study by Oxley \& Fildes (2000) has shown that when the elderly stop driving, their social life would be restricted. The elderly's dependence on car and its impact on their social life are particularly notable in auto-dependant suburbs of Australia where many elderly people are living (Hugo, 2003). Another study by Richard, Gauvin, Gosselin, and Laforest (2009) also demonstrated the frequency of walking episodes, use of public transport, and driving as the major contributors to the elderly's social life. This study also highlighted the importance of perceived accessibility as well as the availability of services located within a 5-min walk of the elderly's residence.

Safety, as a feature of the physical environment, also contributes to the social life of the elderly. In general, people restrict their activities as a result of feeling unsafe. The feeling of unsafety leads to limited social interaction and less social involvement in the community (Taylor, 1988). Similar to the broader population, a feeling of safety in studies relating to the elderly is a significant contributor to their social life. For instance, a study by Burby and Rohe (1990) revealed that elderly residents' perception of crime and feeling unsafe negatively influences their social interaction. The study demonstrated that the fear of crime can isolate elderly households, since it causes residents to restrict their social activities in order to reduce their exposure to victimization. 


\section{Policy Environment}

Defining boundaries of a policy environment and physical and social environments is difficult. The policy environment is not static; it changes constantly to respond to the changing needs of the society. As a part of planning for an ageing population, policies have been introduced to achieve an inclusive and age-friendly community aimed at improving the social life of the elderly. In Queensland, Australia, policies have been introduced to encourage the elderly's participation through volunteering programs, lifelong education and training, and a wide range of social, cultural and recreational activities. This approach also includes strategies to increase awareness of services and facilities that help the elderly to socialise, encourage collaborative design, and support inclusive policies that incorporate diverse cultures and languages (Queensland Government, 2010).

Another part of these policies includes age care services, provided for elderly people based on the levels of assistance they need. In Australia, these include community and residential aged care services, run by not-for-profit, government, and private for-profit organisations. The former provides the elderly with different types and levels of assistance within their own community. The services help the elderly to remain in their communities and thereby maintain their social ties. Residential aged care service, in turn, includes alternative residential lifestyles aimed at supporting the elderly whose needs can no longer be met in their homes (AIHW, 2010; AIHW, 2012). This service requires the elderly to relocate to age-segregated communities which can be challenging. It requires them to leave their community and to leave their social ties that have been shaped over a long time of residency in that neighbourhood. Nevertheless, a majority of factors, including "health status, lack of security, difficulty managing a large property, social isolation, poor public transport, loneliness, desire for alternative lifestyle" (Grant, 2006, p. 101) might cause the elderly to leave their homes and move to age-segregated communities.

Unfortunately, there is very little knowledge about whether migration to these communities would provide the elderly with a more liveable and socially active environment compared with staying in their homes and ageing in place. Stimson and McCrea (2004) proposed a push-pull framework, modelling the decision-making process of retirees in Australia, when they relocate to retirement villages. The study revealed that social isolation is one of the main push factors, the reasons why retirees moved from their home to retirement villages. In another study, Buys (2001) interviewed residents of 25 retirement villages regarding their social interactions. His study revealed that congregate accommodation, such as living in retirement villages, provides the elderly with close proximity with other people, and consequently increases their informal social interaction.

However, age-segregated communities include various types of housing. Design of these communities, their location, and the facilities provided in these communities might be influential in the social life of the elderly living there. Thus, there is a need to conduct more research on the influence of design 
features of these communities on the social life of the elderly. An example of these studies is research conducted by Burby and Rohe (1990), based on an empirical study of ten public housing developments. Their research highlighted the importance of the location of the retirement villages - including quality of the neighbourhood and access to neighbourhood services -, design features, and management of the retirement villages in the social life of elderly people.

\section{Social Environment}

Although there are commonly used definitions of social environment, there is no definition that is universally agreed upon. Conducting a comprehensive review of the definition of the social environment, McNeill, Kreuter, and Subramanian (2006, p. 1012) found three key elements of the social environment: "interpersonal relationships (e.g., social support and social networks), social inequalities (e.g. socioeconomic position and income inequality, racial discrimination), and neighbourhood and community characteristics (e.g., social cohesion and social capital, neighbourhood factors)".

Drawing on the literature reviewed, very few studies have evaluated the impacts of the social dimensions of the environment on the social life of the elderly. A consistent finding is the impact of socio-economic status (SES) on the elderly's social life. A study by Richard et al. (2009) revealed an association between higher levels of education and higher levels of social participation among older adults. Shahtahmasebi and Scott (1996) also found higher levels of social isolation among older working class people.

Some studies have also revealed the influence of racial and ethnic characteristics on the social life of the elderly. A longitudinal study of black and white elderly residents on the south side of Chicago, by Barnes, de Leon, Bienias, and Evans (2004), revealed that older Blacks had smaller size social networks than older Whites. The study suggested that the lower level of social life of the Blacks is probably because of less participation in the labour force in addition to less participation in particular social activities as a result of their SES. In another study, Lindström (2005) also found lower levels of social engagement among people born in other countries compared to the people who are born in the reference country, Sweden.

It is important to note that discussion around the social environment is very complex. The impacts of social environments vary in different contexts. For instance, Schieman's (2005) study of older adults revealed that there is a positive association between neighbourhood disadvantage and social support among black woman who live in areas with greater residential stability. The study also demonstrated that neighbourhood disadvantage is negatively associated with the social support among white men living in areas with low residential stability. The level of social support among residents is important as it is shown in a study by Bowling and Stafford (2007). Their study suggested that elderly residents' perception of low level of social support in their 
neighbourhood is associated with likelihood of low level of social interaction with neighbours.

\section{Gaps in Current Literature and the Areas for Further Research}

A major weakness commonly found in the studies reviewed is a lack of focus on the social life of the elderly in the environmental-public healthgerontological research. Bridging this gap requires further collaboration between disciplines, and conducting more interdisciplinary research. This paper also argues for a need for greater specificity with regard to the heterogeneity of the elderly (WHO, 2002) and their needs. Elderly people are a diverse group in respect to their personal history, culture, SES and health status. Thus, each elderly person's characteristics influence his/her perception of the environment and thereby affect the environmental impacts on their health. More research is needed to assess the diverse needs of the elderly, their diverse responses and finally the diverse environment-person relationships and impacts.

The review also revealed some weaknesses in the studies on the impacts of the physical, policy and social dimensions of the urban environment on the elderly's social life. In the majority of the studies, reviewed, the elderly's perception of the physical environment and its features has not been assessed. This is a critical weakness which requires further research. Relocation in later life is also a topic of debate in the literature on the impacts of the policy environment. Current literature confirms the positive role of age-segregated communities in the social life of the elderly. However, the studies in this field are very few and the theoretical knowledge in this area is limited. The question, here, is should the urban environment be reshaped so that all places work for older people or should older people be relocated to particular places that are well-developed to meet their particular needs. In addition, research has shown that very few social health studies have assessed the impacts of the social environment in which the elderly live. Further research is required to better understand the role of the social environment in the social life of elderly people.

\section{Policy Implications}

The relationship between the environment and the social health of the elderly is complex. Several policy implications become evident from a broader interpretation of the impacts of the urban environment on the social health of the elderly.

Research clearly shows that the provision of green spaces and third places is an important component of an urban environment that supports the social life of the elderly. However, these places are required to be designed in a way that supports the special needs of people as they age. Interactions between elderly people will not occur unless adequate provision is made to support their safety. 
Policies to provide crime prevention information for the elderly as well as policies on Crime Prevention through Environmental Design must be supported to reduce the impacts of crime and fear of crime against elderly people. Urban environments are also required to be accessible to the elderly. The accessibility of the environment must be addressed at the policy level by informed design guidelines on the choice of location, provision of mixed-use, pedestrian-oriented neighbourhoods, and provision of elderly-friendly public transport facilities. These policies also need to be accompanied by programs aimed at increasing the elderly's awareness of facilities and services provided for them. Interaction among the elderly is also influenced by the level of noise in the environment. This might lead to allocating a part of public spaces such as restaurants and cafes, with controlled level of noise, to the elderly. Another alternative might be the provision of public places exclusive to the elderly where their particular needs are addressed. This however, might cause some levels of segregation.

The theory of age segregation is also a subject of much debate in housing studies (Bosman, 2012). Policy needs to find a right balance between spatial segregation, caused by age segregation, and social connection to the rest of the community. Many residents of age-segregated communities develop bonds with each other through shared values, neighbourly support and reciprocity. However, their connection to the wider community, outside of the 'gates' (perceived or real), is often weak. This attachment can be addressed with the choice of the location and size of the age-segregated community and its access to other parts of the urban environment. Provision of social programs by service providers, government agencies, and community groups that encourage the elderly to interact with people in other age cohorts can also lead to better integration of the elderly to the whole community.

The social life of the elderly can also be influenced by the characteristics of the social environment in each urban area. It is notable that the physical, policy, and social environments do not exist independently of each other, and any urban environment is the result of interactions between all these dimensions. Thus, policies aimed at supporting the social life of the elderly are required to take into account the collaborative impacts of all dimensions of the urban environment. Furthermore, planning for the elderly must consider the particular needs of the elderly, caused by their age and health status, in addition to their general characteristics (i.e. education level, culture and lifestyle). Planning for the elderly will not be possible without involving elderly people or their representatives in different levels of planning and development.

\section{Conclusion}

Our study has provided a critical review of the literature on the how the physical, social, and policy dimensions of the environment influence the social life of the elderly, which is an important component of social health. As discussed, third places facilitate social interaction among the elderly as do 
green spaces. The level of noise of the environment, the elderly's feeling of safety and the accessibility of the environment are also found important in their social life. In addition, policies aimed at improving the social participation of the elderly are needed to be implemented in communities with aging population. While there are only a few studies on the migration in late life and its influence on social life, available literature is confirming the role of agesegregated communities in encouraging social encounters among their residents. However, careful design of these communities is also highlighted in the literature.

The impacts of the urban environment are not limited to its physical and policy dimensions. The social environment, although hard to define, is also found influential in the social life of the elderly. SES, racial and ethnic characteristics, and the level of social support are the social environmental features highlighted as important factors in the social life of the elderly. Undoubtedly, further research is needed to expand the understanding of the urban environment and its dimensions influencing the social life of the elderly and consequently their health and well-being.

\section{References}

Australian Institute of Health and Welfare (AIHW). 2010. Residential aged care in Australia 2010-11: A statistical overview. AIHW, Canberra, ACT.

Australian Institute of Health and Welfare (AIHW). 2012. Aged care packages in the community 2010-11: a statistical overview. AIHW, Canberra, ACT.

Banister, D. and Bowling, A. 2004. Quality of life for the elderly: the transport dimension. Transp. policy. 11, 2 (Apr. 2004), 105-115. DOI= http://doi.org/10. 1016/S0967-070X(03)00052-0.

Barnes, L. L., de Leon, C. F. M., Bienias, J. L., and Evans, D. A. 2004. A longitudinal study of Black-White differences in social resources. J. Gerontol. B Psychol. Sci. Soc. Sci. 59B, 3 (May 2004), S146-S153. DOI= http://doi.org/10.1093/geronb/ 59.3.S146.

Bosman, C. 2012. Gerotopia: Risky housing for an ageing population. Hous. Theory. Soc. 29, 2 (Jan. 2012), 157-171. DOI= http://doi.org/10.1080/14036096.2011. 641259.

Bowling, A. and Stafford, M. 2007. How do objective and subjective assessments of neighbourhood influence social and physical functioning in older age? Findings from a British survey of ageing. Soc. Sci. Med. 64, 12 (June 2007), 2533-2549. DOI= http://doi.org/10.1016/j.socscimed.2007.03.009.

Burby, R. J. and Rohe, W. M. 1990. Providing for the housing needs of the elderly. $J$. Am. Plann. Assoc. 56, 3 (July 1990), 324-340. DOI= http://doi.org/10.1080/0194 4369008975776.

Buys, L. R. 2001. Life in a retirement village: implications for contact with community and village friends. Gerontology. 47, 1 (Jan. 2001), 55-59. DOI= http://doi.org/10.1159/000052771.

Cheang, M. 2002. Older adults' frequent visits to a fast-food restaurant: Nonobligatory social interaction and the significance of play in a "third place". J. Aging Stud. 16, 3 (Aug. 2002), 303-321. DOI= http://doi.org/10.1016/S0890-4065(02)00052$\underline{X}$. 
Ciorba, A., Bianchini, C., Pelucchi, S., and Pastore, A. 2012. The impact of hearing loss on the quality of life of elderly adults. Clin. Interv. Aging. 7 (June 2012), 159-163. DOI= http://doi.org/10.2147/CIA.S26059.

Clarke, P. and Nieuwenhuijsen, E. R. 2009. Environments for healthy ageing: a critical review. Maturitas. 64, 1 (Sept. 2009), 14-19. DOI= http://doi.org/10.1016 /j.maturitas.2009.07.011.

Crosby, R. A., Salazar, L. F., and DiClemente, R. J. 2011. Ecological approaches in the new public health. In Health Behavior Theory for Public Health: Principles, Foundations, and Applications, R. J. DiClemente, L. F. Salazar, and R. A. Crosby, Eds. Jones \& Bartlett Learning, Burlington, MA, 231-251.

Donald, C. A., Ware Jr, J. E., Brook, R. H., and Davies-Avery, A. 1978. Conceptualization and measurement of health for adults in the health insurance study: Vol. IV, Social health. Rand Corporation, Santa Monica, CA.

Dumont, C. 2009. Ecological Approaches to Health: Interactions between Humans and Their Environment. Nova Science Publishers, New York, NY.

Grant, B. C. 2006. Retirement villages: An alternative form of housing on an ageing landscape. Soc. Policy. J. N. Z. 27 (Mar. 2006), 100-113.

Greenblatt, H. N. 1976. Measurement of social well-being in a general population survey. California State Department of Health, Berkeley, CA.

Guralnik, J. M., LaCroix, A. Z., Abbott, R. D., Berkman, L. F., Satterfield, S., Evans, D. A., and Wallace, R. B. 1993. Maintaining mobility in late life. I. Demographic characteristics and chronic conditions. Am. J. Epidemiol. 137, 8 (Apr. 1993), 845857.

Gurland, B. J., Yorkston, N. J., Stone, A. R., Frank J. D., and Fleiss , J. L. 1972. The Structured and Scaled Interview to Assess Maladjustment (SSIAM) I. Description, rationale, and development. Arch Gen Psychiatry. 27, 2 (Aug. 1972), 259-264.

Hugo, G. 2003. Australia's ageing population: some challenges for planners. Australian. Planner. 40, 2 (Apr. 2003), 109-118. DOI= http://doi.org/10.1080/ 07293682.2003 .9995264$.

Institute of Medicine of the National Academies. 2003. The Future of the Public's Health in the 21st Century. National Academies Press, Washington, D.C.

Kweon, B.-S., Sullivan, W. C., and Wiley, A. R. 1998. Green common spaces and the social integration of inner-city older adults. Environ. Behav. 30, 6 (Nov. 1998), 832-858. DOI= http://doi.org/10.1177/001391659803000605.

Lindström, M. 2005. Ethnic differences in social participation and social capital in Malmö, Sweden: a population-based study. Soc. Sci. Med. 60, 7 (Apr. 2005), 1527-1546. DOI= http://doi.org/10.1016/j.socscimed.2004.08.015.

McNeill, L. H., Kreuter, M. W., and Subramanian, S. 2006. Social environment and physical activity: a review of concepts and evidence. Soc. Sci. Med. 63, 4 (Aug. 2006), 1011-1022. DOI= http://doi.org/10.1016/j.socscimed.2006.03.012.

Oldenburg, R. 1989. The great good place: Cafés, coffee shops, community centers, beauty parlors, general stores, bars, hangouts, and how they get you through the day. Paragon House, New York, NY.

Oxley, J. and Fildes, B. 2000. Retiring from Driving: The Process of Reduction and Cessation of Driving and the Role of a Handbook to Assist in This Process. In Proceedings of the Older Road User Safety Symposium (Brisbane, Australia, November 26, 2000). CARRS-Q, Brisbane, QLD, 57-63.

Phillips, D., Siu, O., Yeh, A., and Cheng, K. 2005. Ageing and the urban environment. In Ageing and place: Perspectives, policy, practice, G. J. Andrews and D. R. Phillips, Eds. Routledge, London, 147-163. 
Queensland Government. 2010. Positively Ageless: Queensland Seniors Strategy 2010-20. Queensland Government.

Renne, K. S. 1974. Measurement of social health in a general population survey. Soc. Sci. Res. 3, 1 (Mar. 1974), 25-44. DOI= http://doi.org/10.1016/0049-089X(74) 90017-9.

Richard, L., Gauvin, L., Gosselin, C., and Laforest, S. 2009. Staying connected: neighbourhood correlates of social participation among older adults living in an urban environment in Montreal, Quebec. Health. Promot. Int. 24, 1 (Mar. 2009), 46-57. DOI= http://doi.org/10.1093/heapro/dan039.

Rosenbaum, M. S. 2006. Exploring the social supportive role of third places in consumers' lives. J. Serv. Res-US, 9, 1 (Aug. 2006), 59-72. DOI=http://doi.org/ $10.1177 / 1094670506289530$.

Schieman, S. 2005. Residential stability and the social impact of neighborhood disadvantage: A study of gender-and race-contingent effects. Soc. Forces. 83, 3 (June 2005), 1031-1064. DOI= http://doi.org/10.1353/sof.2005.0045.

Shahtahmasebi, S. and Scott, A. 1996. Social isolation and loneliness in old age: Review and model refinement. Ageing Soc. 6 (May 1996), 333-358. DOI= http:// doi.org/10.1017/S0144686X00003457.

Stimson, R. J. and McCrea, R. 2004. A push-pull framework for modelling the relocation of retirees to a retirement village: The Australian experience. Environ. Plann. A. 36, 8 (Aug. 2004), 1451-1470. DOI= http://doi.org/10.1068/a36206.

Taylor, R. B. 1988. Human Territorial Functioning: An Empirical, Evolutionary Perspective on Individual and Small Group Territorial Cognitions, Behaviors, and Consequences. Cambridge University Press, Cambridge, NY.

Weaver, N., Williams, J.L., Weightman, A.L., Kitcher, H.N., Temple, J.M.F., Jones, P., and Palmer, S. 2002. Taking STOX: developing a cross disciplinary methodology for systematic reviews of research on the built environment and the health of the public. J.E.C.H. 56,1 (Jan. 2002), 48-55. DOI= http://doi.org/10.11 36/jech.56.1.48.

World Health Organisation (WHO). 1946. Preamble to the Constitution of the World Health Organization as adopted by the International Health Conference, New York, June 19-22, 1946. WHO, Geneva, GE.

World Health Organisation (WHO). 1986. Ottawa charter for health promotion. WHO, Geneva, GE.

World Health Organisation (WHO). 2002. Active ageing: A policy framework. WHO, Geneva, GE.

World Health Organisation (WHO). 2007. Global Age-friendly Cities: A Guide. WHO, Geneva, GE. 